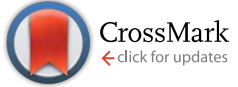

Cite this: RSC Adv., 2017, 7, 16763

Received 5th January 2017

Accepted 26th February 2017

DOI: 10.1039/c7ra00172j

rsc.li/rsc-advances

\section{Comparative effect of cationic gemini surfactant and its monomeric counterpart on the conformational stability and activity of lysozyme $\uparrow$}

\author{
Taruna Sharma, ${ }^{a}$ Neeraj Dohare, ${ }^{a}$ Meena Kumari, ${ }^{a}$ Upendra Kumar Singh, ${ }^{a}$ \\ Abbul Bashar Khan, ${ }^{a}$ Mahendra S. Borse ${ }^{b}$ and Rajan Patel ${ }^{* a}$
}

Protein interactions with surfactants are dependent on their physiochemical properties. The effect of cationic gemini surfactant hexanediyl- $\alpha, \omega$-bis-( $N$-(2-hydroxyethyl)- $N$-methylhexadecylammonium dibromide) on the stability and activity of hen egg white lysozyme was compared with its monomeric counterpart $N$-(2-hyroxyethyl)- $N, N$-dimethylhexadecylammonium bromide at pre and post micellar concentrations. This study utilizes circular dichroism (CD), steady-state fluorescence spectroscopy, extrinsic fluorescence spectroscopy, time-resolved fluorescence spectroscopy, UV-visible spectroscopy, molecular docking and turbidity assays to resolve the conformational stability and antibacterial activity of lysozyme in the presence of surfactants. Micelles of both cationic surfactants were observed to stabilize the conformation of the protein, however, gemini was found to stabilize it in a much higher micellar concentration range. Detailed analysis of the time-resolved fluorescence spectroscopy results suggests contribution of the lifetime values of Trp62 and Trp108 to the overall conformation change of lysozyme with the increase in concentration of the respective surfactants, which is further correlated with the steady-state fluorescence and CD spectroscopy results. Furthermore, from the CD analysis it was found that the cationic single chain surfactant strongly perturbs the secondary and tertiary structure of the protein as compared to the gemini surfactant. Through docking results, it was found that the gemini surfactant binds weakly with lysozyme as compared to the single chain surfactant. Specifically, the antibacterial activity of lysozyme was found to be increased in the presence of cationic gemini surfactant, which extrapolates the use of these surfactants in pharmaceutics and industries.

\section{Introduction}

Protein-surfactant studies have been under thorough investigation since the late $18^{\text {th }}$ century ${ }^{1}$ and there are a plethora of well-established facts related to this domain. The effect of surfactant on protein stability depends on the type of surfactant forming specific interactions. ${ }^{2}$ Protein conformation dynamics majorly involve hydrophobic effects ${ }^{3}$ and the degree of attraction for water. ${ }^{4}$ It has already been reported that monomeric detergents bind to the native state as conventional ligands, that is, they bind to a small number of sites in a saturable manner ${ }^{5,6}$ (through hydrophobic and electrostatic interactions mainly) and generally micelles act as denaturants. ${ }^{7}$ The process of

${ }^{a}$ Biophysical Chemistry Laboratory, Centre for Interdisciplinary Research in Basic Sciences, Jamia Millia Islamia (A Central University), New Delhi, India. E-mail: rpatel@jmi.ac.in; rajanpatelpcy@gmail.com; Fax: +91 11 26983409; Tel: +91 8860634100

${ }^{b}$ Department of Chemistry, Uttamrao Patil College Dahivel Taluka-sakri, Dhule, Maharashtra, India

$\dagger$ Electronic supplementary information (ESI) available. See DOI: 10.1039/c7ra00172j denaturation depends on the effect of denaturants on the water structure and on the hydrophobic interactions in the tertiary structure of the protein ${ }^{8,9}$ which leads to nonspecific cooperative interactions. Unlike anionic surfactants, cationic surfactants bind weakly to the protein and are less efficient then anionic surfactants in promoting the cooperative transition. They are also known to maintain the three dimensional structure of the protein at considerable high concentrations ${ }^{2}$ even above their cmc values. ${ }^{\mathbf{1 0}}$ This difference in binding pattern of cationic surfactants is attributed due to smaller relevance of electrostatic interactions at the $\mathrm{pH}$ 's of interest, ${ }^{\mathbf{1 1}}$ side chains involved in the basic protein-surfactant interaction (hydrophobic contribution and electrostatic interaction of charged residues) at monomeric concentrations and due to the difference in micellar structure of these surfactants at their micellar concentrations as explained by Otzen. ${ }^{7}$

In addition, the structural and functional stability of some proteins can be more efficiently determined by analyzing their catalytic activity. It has already been mentioned that aqueous micelles can act as catalysts or inhibitors for enzymes, depending on the nature of the surfactants (cationic, anionic or neutral) forming the micelles. ${ }^{\mathbf{1 2}}$ Cationic surfactants are known 


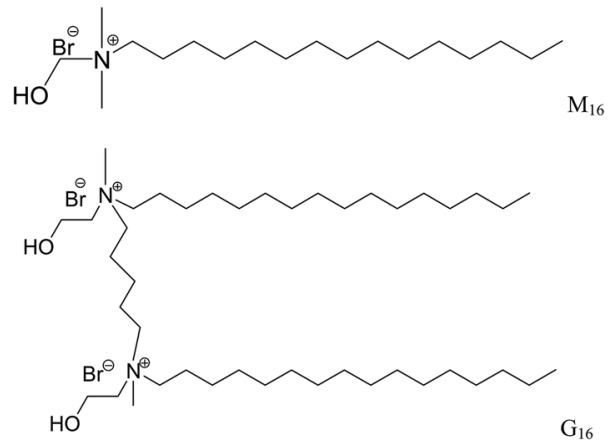

Scheme 1 Structure of $N$-(2-hydroxyethyl)-N,N-dimethylhexadecyl ammonium bromide $\left(M_{16}\right)$ and hexanediyl- $\alpha, \omega$-bis- $N$-(2-hydroxyethyl) $-N$-methylhexadecyl ammonium dibromide $\left(G_{16}\right)$.

to increase or stabilize the activity of certain enzymes. In contrast to anionic surfactants, ${ }^{13}$ Lu et al. ${ }^{14}$ and Guzman et al. ${ }^{15}$ found catalytic activity of surface active enzymes like lysozyme and pepsin respectively and observed them to be reactivated and stabilized by interaction with cationic surfactants probably because of the lesser involvement of above mentioned electrostatic interactions.

Some recent reports on new generation surface active agents called as "Gemini surfactant" also suggests their potential role in protein stability and activity. ${ }^{16,17}$ Interaction of gemini surfactants with proteins suggest that they have stronger binding with proteins as compared to conventional surfactants. ${ }^{18-20}$ This difference in binding is majorly governed due to dissimilarity in their physiochemical properties they possess due to the presence of two long hydrocarbon chains and two ionic groups attached covalently to a spacer group. They have better solubility, lower cmc value and Krafft temperature. ${ }^{21}$ Also, they have unique binding properties due to their strong dependence on spacer length, ${ }^{22}$ special aggregate morphology, and strong hydrophobic microdomain. ${ }^{21}$

Recently we have reported the possible role of gemini surfactants in refolding of globular protein ${ }^{23}$ and stability of membrane bound peptide. ${ }^{24}$ Present communication is an attempt to get much deeper insight on the comparative effect of biscationic methyl ethanol amine gemini surfactant
$\mathrm{C}_{16} \mathrm{H}_{33}\left(\mathrm{CH}_{3}\right)_{2} \mathrm{C}_{2} \mathrm{H}_{4} \mathrm{OHN}{ }^{+}-\left(\mathrm{CH}_{2}\right)_{6}-\mathrm{N}^{+} \mathrm{C}_{2} \mathrm{H}_{4} \mathrm{OH}\left(\mathrm{CH}_{3}\right)_{2} \mathrm{C}_{16} \mathrm{H}_{33} 2 \mathrm{Br}^{-}$ abbreviated as $\mathrm{G}_{16}$ with spacer length - $\left(\mathrm{CH}_{2}\right)_{6}$ - and its monomeric counterpart $\mathrm{C}_{16} \mathrm{H}_{33}\left(\mathrm{CH}_{3}\right)_{2} \mathrm{C}_{2} \mathrm{H}_{4} \mathrm{OHN}^{+} \mathrm{Br}^{-}$abbreviated as $\mathbf{M}_{16}$ on the structural stability and antibacterial activity of hen egg white lysozyme (HEWL) using various spectroscopic techniques and molecular docking method. The structure of $\mathbf{M}_{16}$ and $\mathrm{G}_{16}$ has been depicted in Scheme 1 .

Lysozyme is a well studied $14603 \mathrm{Da}$ globular protein. It is involved in protein misfolding disease, known as nonneuropathic systemic amyloidoses ${ }^{25}$ hence, understanding the effect of different ligands on structural and functional stability of this enzyme is highly significant. Lysozyme has two domains; $\alpha$-domain having four $\alpha$-helices and a C-terminal $3_{10}$ helix and $\beta$-domain which contain triple-stranded antiparallel $\beta$-sheets, a $3_{10}$ helix, and a long loop. ${ }^{26}$ The two domains are linked through short double stranded antiparallel $\beta$-sheet. It has total 129 amino acids with four disulphide bonds in its tertiary structure. ${ }^{27}$ In aqueous solution, lysozyme (Isoelectric point, IP 11.35) has a $\mathrm{pH}$ of 6.5 with a net positive charge of $8 .^{28}$

Interaction of lysozyme with anionic surfactant like SDS has been studied in detail $^{29}$ and is known to strongly perturb its three dimensional structure due to the presence of strong electrostatic interactions. Cationic surfactants possess comparatively weaker interaction with lysozyme because of the obvious electrostatic repulsion at physiological pH. However, they form weak electrostatic interactions with negatively charged amino acids (Asp and Glu) ${ }^{30}$ present in lysozyme. Chatterjee et al. ${ }^{31}$ using micro-calorimetry found that hydrophobic interaction dominates over electrostatic repulsion resulting in lysozyme-CTAB aggregate formation. The effect of gemini surfactant on lysozyme have also been reported previously, ${ }^{19,32,33}$ however relatively less interaction studies have been made till now. The aim of the present study is to decipher the binding interaction of $\mathrm{M}_{16}$ and $\mathrm{G}_{16}$ on the conformational stability and antibacterial activity of HEWL. The interaction pattern of $\mathrm{M}_{16}$ and $\mathrm{G}_{16}$ with lysozyme before and after $\mathrm{cmc}$ has been shown in Scheme 2. We hope that this study will endow greater landscape on the difference in binding of respective surfactants specifically with HEWL which will prove to be helpful from medicinal and pharmaceutical point of view. In addition, we hope that it will provide wide understanding on

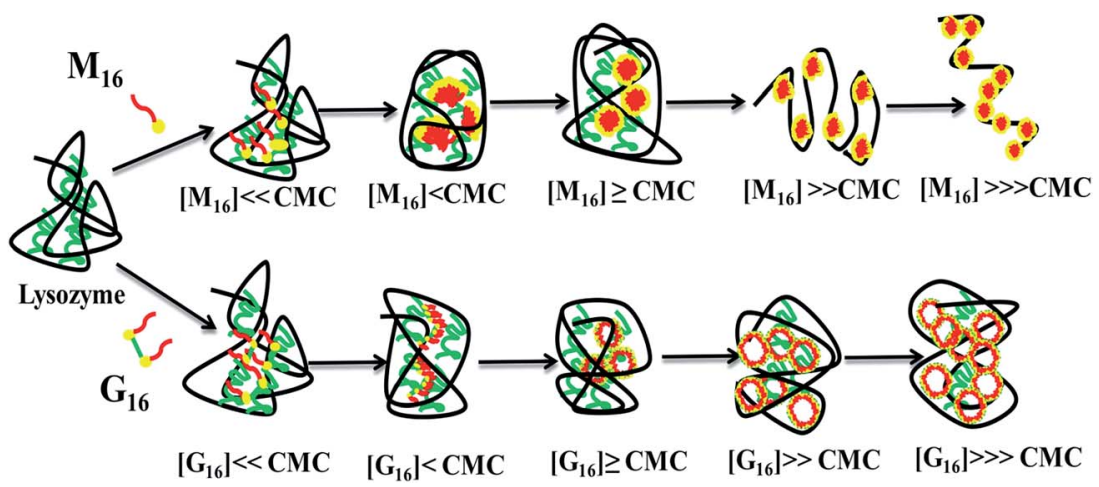

Scheme 2 Scheme showing the interaction pattern of $M_{16}$ and $G_{16}$ with lysozyme before and after $C M C$. 
the structural and functional properties HEWL for augmenting the application of this enzyme in food preservation and as an effective antibiotic.

\section{Experimental section}

\subsection{Materials}

The details of all chemicals employed were summarized in Table $1 . \mathrm{M}_{16}$ and $\mathrm{G}_{16}$ surfactants were synthesized in our lab using protocol mentioned elsewhere. ${ }^{34,35}$ All the chemicals and reagents used were of analytical grade. Millipore water of specific conductance $2-2.5 \mu \mathrm{S}$ was used throughout experiments. The pH measurements were carried out with a Khera Microprocessor $\mathrm{pH}$ meter (India) using a combined electrode consisting of glass and reference electrodes as a single entity.

\subsection{Sample preparation}

The stock solution of protein was prepared in $10 \mathrm{mM}$ phosphate buffer. It was then extensively dialyzed and filtered using $0.22 \mu \mathrm{M}$ millipore syringe filter. The concentration of the stock solution was monitored by UV-visible spectrophotometer using molar extinction coefficient of HEWL $\varepsilon_{280}=37932 \mathrm{M}^{-1} \mathrm{~cm}^{-1} .{ }^{36}$ Protein working solution of $0.3 \mathrm{mg} \mathrm{ml}^{-1}(\sim 20 \mu \mathrm{M})$ was used in far-UV CD, UV-visible, steady-state and extrinsic fluorescence and time resolved fluorescence spectroscopy measurements. The stock solutions of surfactants were made in analytical grade millipore water. The cme values $\mathrm{M}_{16}$ and $\mathrm{G}_{16}$ were measured by conductivity experiment and they were found to be $\sim 2.10 \times 10^{-4} \mathrm{M}$ and $\sim 3.63$ $\times 10^{-6} \mathrm{M}$ which is in good agreement with the reported values. ${ }^{34,37}$ The respective surfactants do not show any absorption in the protein absorbing region in all the concentrations used. All the working concentrations of samples were prepared by adding an appropriate amount of surfactant from its stock solution into the HEWL solution. All the samples of desired concentrations were incubated overnight at room temperature in all the experiments. Incubating surfactant-protein samples at higher concentration is necessary for maintaining equilibration of protein/surfactant ratio ${ }^{12}$ which otherwise decreases.

\subsection{Methods}

2.3.1 Steady-state fluorescence measurements. Steady-state fluorescence measurements were performed on a Cary Eclipse spectrofluorimeter (Varian, USA) equipped with a $150 \mathrm{~W}$ xenon lamp using $1 \mathrm{~cm}$ path length quartz cuvettes at $298 \mathrm{~K}$. The excitation and emission slits with a band pass of $2.5 \mathrm{~nm}$ and $5 \mathrm{~nm}$ were used for steady-state fluorescence experiments. Fluorescence of the HEWL was measured at an excitation wavelength of $280 \mathrm{~nm}$ and the spectra were recorded within the wavelength range of $300-500 \mathrm{~nm}$. Corrections for inner filter effect were made using the following equation. ${ }^{38}$

$$
F=F_{\text {obs }} \operatorname{antilog}\left[\left(A_{\text {ex }}+A_{\text {em }}\right) / 2\right]
$$

where, $F$ is the corrected fluorescence intensity and $F_{\mathrm{obs}}$ is the background subtracted observed fluorescence intensity. The values $A_{\mathrm{ex}}$ and $A_{\mathrm{em}}$ are the measured absorbance at the excitation and emission wavelengths. The synchronous fluorescence spectra were measured by the same spectrofluorimeter at two different wavelength intervals $(\Delta \lambda) 15$ and $60 \mathrm{~nm}$, respectively ${ }^{39}$ at $298 \mathrm{~K}$.

2.3.2 Extrinsic fluorescence measurements. Extrinsic fluorescence measurements were done by probing pyrene to the hydrophobic pocket of HEWL by using the same instrument as in steady state fluorescence experiments. A solution of pyrene was prepared in ethanol and constant concentration of pyrene $(2 \mu \mathrm{M})^{40}$ was carefully maintained in all the samples. During sample preparation, the excess ethanol in pyrene was removed by passing nitrogen gas. The excitation wavelength of HEWL probed with pyrene was maintained at $337 \mathrm{~nm}$ and emission was monitored between $350-450 \mathrm{~nm}^{41}$ at $298 \mathrm{~K}$. Both the excitation and emission slit width were maintained at $2.5 \mathrm{~nm}$ during the course of measurements.

2.3.3 Time-resolved fluorescence measurements. Timeresolved fluorescence measurements were performed at $298 \mathrm{~K}$, using a single-photon counting spectrometer equipped with pulsed nanosecond LED excitation heads at $280 \mathrm{~nm}$ (Horiba, Jobin Yvon, IBH Ltd, Glasgow, UK). The fluorescence lifetime data were measured to 10000 counts in the peak unless otherwise indicated. The instrumental response function was recorded sequentially using a scattering solution and a time calibration of 114 ps per channel. Data were analyzed using a sum of exponentials, employing a nonlinear least squares reconvolution analysis of the form: ${ }^{42}$

$$
f(t)=\sum_{i=1}^{n} a_{i} \exp \left(\frac{-\tau}{\tau_{i}}\right)
$$

Table 1 Sample source and purity

\begin{tabular}{llll}
\hline Chemical name & Source & Purity & Purification method \\
\hline HEWL & Sigma-Aldrich & $\geq 98.0 \%$ & Dialyzed and filtered \\
Micrococcus lysodickticus & Sigma-Aldrich & - & - \\
$\mathrm{NaH}_{2} \mathrm{PO}_{4}{ }^{a}$ & Sigma-Aldrich & $98.0 \%$ & - \\
$\mathrm{Na}_{2} \mathrm{HPO}_{4}{ }^{b}$ & Sigma-Aldrich & $98.0 \%$ & - \\
Pyrene & Sigma-Aldrich & $98.0 \%$ & - \\
Ethanol & Merck & $99.5 \%$ & - \\
Acetone & Merck & $99.0 \%$ & - \\
$\mathrm{M}_{16}$ & Synthesized & $99.0 \%$ & Recrystallization \\
$\mathrm{G}_{16}$ & Synthesized & $99.0 \%$ & Recrystallization
\end{tabular}

${ }^{a}$ Sodium phosphate monobasic. ${ }^{b}$ Sodium phosphate dibasic. 
where $\tau_{i}$ are the decay times, $a_{i}$ is the relative contribution of the components at $t=0$ and $n$ is the number of decay times.

The goodness of fit was judged in terms of both a chisquared $\left(\chi^{2}\right)$ value and weighted residuals. Time-resolved fluorescence decays were analyzed making use of the impulse response function (IBH DAS6 software). The average fluorescence lifetimes $(\langle\tau\rangle)$ of HEWL for the decay curves were calculated from the decay times and the relative contribution of the components using the following equation: ${ }^{38}$

$$
\langle\tau\rangle=\frac{\sum a_{i} \tau_{i}^{2}}{\sum a_{i} \tau_{i}}
$$

A fit was considered acceptable when plots of the weighted residuals and the autocorrelation function showed random deviation about zero with a minimum $\chi^{2}$ value approaching $1 .^{38}$

2.3.4 Circular dichroism measurements. Circular dichroism (CD) spectra were recorded on a Jasco-1500 spectropolarimeter, equipped with a peltier-type temperature controller (PTC-348 WI). All the CD measurements were carried out at $298 \mathrm{~K}$ with a thermostatically controlled cell holder attached to a Neslab RTE-110 water bath with an accuracy of $\pm 0.1 \mathrm{~K}$. Changes in the secondary and tertiary structure of the protein were monitored in the far-UV region (200-250 nm) and near UV region (250-300 nm). The protein concentrations used for near-UV CD was $0.6 \mathrm{mg} \mathrm{ml}^{-1}$ respectively. The signal from the reference sample containing buffer and the detergent was subtracted from the CD signal for all measurements. CD instrument was regularly calibrated with D-10camphorsulfonic acid. ${ }^{43}$ To improve the signal-to-noise ratio, four accumulations were made for each scan. CD data was converted to concentration independent parameter, the mean residue ellipticity, $[\theta]\left(\mathrm{deg} \mathrm{cm}^{2} \mathrm{dmol}^{-1}\right)$ using the relation:

$$
[\theta]_{\lambda}=\frac{M_{\mathrm{o}} \theta_{\lambda}}{10 l c}
$$

where $\theta_{\lambda}$ is the observed ellipticity in mill degrees at wavelength $\lambda, M_{\mathrm{o}}$ is the mean residue weight of the protein, $c$ is the protein concentration in milligrams per milliliter, and $l$ is the pathlength of the cell in centimeters. The ellipticity values at $208 \mathrm{~nm}\left(\theta_{208 \mathrm{~nm}} / \mathrm{mdeg}\right)$ were used to calculate the $\alpha$-helical content of HEWL using the following equation:

$$
\alpha \text {-Helix }(\%)=\frac{-\mathrm{MRE}_{208}-4000}{33000-4000} \times 100
$$

The value 4000 is the MRE of the $\beta$-sheet and random coil conformation cross at $208 \mathrm{~nm}$ and 33000 is the MRE value of a pure $\alpha$-helix at $208 \mathrm{~nm}^{\mathbf{4 4}}$

2.3.5 UV-visible spectroscopy. Absorption spectra were recorded on Analytik Jena Specord-250 spectrophotometer (USA) with quartz cuvettes of $1 \mathrm{~cm}$ at $298 \mathrm{~K}$ equipped with aircooled peltier temperature controller. Slit width were maintained at $1 \mathrm{~nm}$ and spectra was recorded from $200-450 \mathrm{~nm}$ and peak at $280 \mathrm{~nm}$ was monitored.

2.3.6 HEWL activity assay. HEWL enzymatic activity was measured by using Shimadzu UV-visible spectrophotometer 2100 (model number 1601) which monitors the turbidity of the solution (cell lysis) in a time dependent manner using protocol reported earlier. ${ }^{45}$ Sodium phosphate buffer ( $50 \mathrm{mM}$, pH 6.5) was used for HEWL stock solution $\left(1 \mathrm{mg} \mathrm{ml}^{-1}\right)$ and bacterial cell stock suspension $\left(3 \mathrm{mg} \mathrm{ml}^{-1}\right)$ preparation. The enzyme activity of free HEWL and mixtures were determined after incubating HEWL solutions containing the different concentration of surfactant for $4 \mathrm{~h}$. The measurements were run for 500 seconds using $10 \mathrm{~mm}$ cell length. The band width was kept at $2 \mathrm{~nm}$ for all the runs. To observe the enzyme activity of HEWL, $3 \mathrm{ml}$ of $M$. lysodeikticus suspension (containing $100 \mu \mathrm{l}$ of stock) was added to the $1 \mathrm{~cm}$ quartz cuvette. After that $20 \mu \mathrm{l}$ of free $\mathrm{HEWL} / \mathrm{mixt}$ re was added to the cuvette and the dynamic absorbance was recorded (scanning time $300 \mathrm{~s}$ ). The decrease in apparent absorbance was measured due to a decrease in the light scattering intensity of the solution at $450 \mathrm{~nm}$ at $298 \mathrm{~K}$. Measurements were run with constant stirring at $350 \mathrm{rpm}$. The obtained absorbance curves were linear fitted using Origin 8.5 data analysis tool. The percent relative activity (\% RA) was calculated by using the following relation

$$
\% \mathrm{RA}=\frac{k_{\text {mix }}}{k_{\text {free }}} \times 100
$$

where $k_{\mathrm{mix}}$ is the initial slope of the dynamic mixture of HEWL and surfactant complex and $k_{\text {free }}$ is the initial slope of the dynamic absorbance curve of the free HEWL.

2.3.7 Molecular docking. The possible binding conformation of the respective surfactants with HEWL was computed by using AutoDock vina. The 3D structure of HEWL was downloaded from protein data bank (PDB) using ID: 6LYZ. ${ }^{46}$ It was further prepared in the software by removing hetatom and water molecules. After this, additional hydrogen atoms were added to the protein. Structures of surfactants were prepared using Chemdraw ultra and their energy was minimized using a MM2 force field. The torsion tree was selected in AutoDock software and the torsion angles of the ligand were identified. Blind docking was carried out by defining the grid size to 48,46 , and 82 along $x, y, z$ axis with grid size $0.375 \AA$. The grid center was set as $3.729 \AA$, 23.232 $\AA$, and $21.053 \AA$ along $x, y$ and $z$-axis. Default parameters were used as described in AutoDock vina manual. Total of 10 numbers of runs were carried out and then minimum energy conformers were picked according to the ranking and scoring. The analysis of docking was done by AutoDock tools (ADT) and was visualized by using PyMOL and discovery studio 4.0.

\section{Results and discussion}

\subsection{Circular dichroism spectroscopy}

CD spectroscopy is an absorption-based technique and gives information about the secondary and tertiary structure of the protein. In the far-UV region of the spectrum (240-180 nm), different forms of regular secondary structure found in proteins give rise to characteristic CD spectra. The CD spectrum in this region can be analyzed in terms of the content of $\alpha$-helix, $\beta$ sheet, $\beta$-turn, etc. ${ }^{47}$ Where, in the near-UV region $(320-260 \mathrm{~nm})$ CD signals principally arises from the aromatic side chains Phe, Tyr and Trp and it provides a detailed fingerprint of the tertiary structure of the protein. ${ }^{47}$ 
In the present study, far-UV CD spectroscopy was used in order to monitor the changes induced by $\mathrm{M}_{16}$ and $\mathrm{G}_{16}$ on the secondary structure of HEWL. From the spectrum shown in Fig. 3, it can be clearly seen that HEWL untreated with $\mathbf{M}_{16}$ and $\mathrm{G}_{16}$ gives a characteristic negative peak at $208 \mathrm{~nm}$ and $222 \mathrm{~nm}$ signifies the presence of $\alpha$-helix in HEWL. The percentage of $\alpha$ helix content at $208 \mathrm{~nm}$ was calculated by using eqn (5) and values were reported in Table S1. $\dagger \alpha$-Helical content of pure HEWL was found to be $\sim 42 \%$ which is in good agreement as mentioned by Sethuraman et al. ${ }^{\mathbf{2 6}}$

It was observed that addition of $M_{16}$ (Fig. 1(a)) in the concentration range from $8.26 \times 10^{-8} \mathrm{M}$ to $1.50 \times 10^{-3} \mathrm{M}$, the $\alpha$-helical content of HEWL marginally increased from $42 \%$ to $45 \%$. Signal at $\mathrm{M}_{16}$ concentration $3.20 \times 10^{-3} \mathrm{M}$ there was a decrease in $\alpha$-helical content observed from $45 \%$ to $39 \%$. In case of $\mathrm{G}_{16}$ (Fig. 1(b)), the $\alpha$-helical content was found be increased from $42 \%$ to $45 \%$ in the same way as in case of $\mathrm{M}_{16}$, however, in the concentration range from $8.26 \times 10^{-8} \mathrm{M}$ to 2.10 $\times 10^{-4} \mathrm{M}$. At concentration $3.0 \times 10^{-4} \mathrm{M}$ an overlapping spectrum just like that of native HEWL was observed with a subtle blue shift of $206 \mathrm{~nm}$. Signal at $1.5 \times 10^{-3} \mathrm{M} \mathrm{G}_{16}$ was observed to get shifted in upward direction which signifies destabilizing effect of surfactant on the secondary structure of the protein. The variation in signals at $208 \mathrm{~nm}$ can be more clearly analyzed in Fig. 2 at various concentrations of both the surfactants. Owing to the limitation of far-UV CD spectroscopy, the stability effect by $\mathrm{M}_{16}$ and $\mathrm{G}_{16}$ at the concentration above $3.20 \times 10^{-3} \mathrm{M}$ and $1.5 \times 10^{-3} \mathrm{M}$ respectively, could not be measured as far-UV CD signals above these concentrations could not be deconvoluted due to high noise/signal ratio, as also observed in some others protein-surfactant studies at higher surfactant concentrations. ${ }^{12}$ However, due to the shift of spectrum in an upward direction (Fig. 2) it can be assumed that after these concentrations of $\mathrm{M}_{16}$ and $\mathrm{G}_{16}$ the helical content will decrease.

Thus, it can be concluded from the results that monomeric, as well as micellar forms of both the surfactants are involved in stabilization of secondary structure of HEWL up to certain concentration range. Cationic surfactant can bind to the positively charged HEWL through weak electrostatic (with

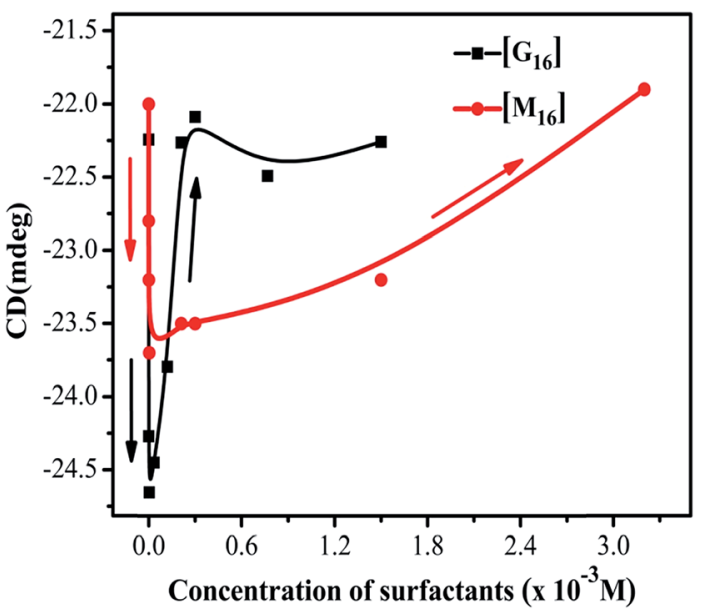

Fig. 2 Variation in far-UV CD signals at $208 \mathrm{~nm}$ representing increase (downward arrows) and decrease (upward arrows) in $\alpha$-helical content of HEWL with respect to increase in concentration of $M_{16}$ (red) and $G_{16}$ (black).

negatively charged residues like Glu and Asp) and strong hydrophobic interactions. However, its stabilizing effect on the secondary structure of HEWL is imparted may be due to the positive charge associated with it, as elucidated in a study by Gospodarczyk et $a .^{32}$ The increase in $\alpha$-helical content can be elucidated due to the formation of the hydrophobic linkage between the hydrophobic chains and non-polar residues present on HEWL causes a local increase in the $\alpha$-helical content of the protein as also observed in a study by Gull et al. ${ }^{20}$ and Wang et $a .^{48}$ In the case of $\mathrm{G}_{16}$, the stabilizing effect on HEWL cannot be attributed to the positive charge present on the two head groups. The reason for this discrepancy can be explained due to the presence of longer spacer group ${ }^{17}$ which causes lower charge density on the surfactant and thus possibly it binds weekly with HEWL as compared to $\mathrm{M}_{16}$ unlike of some reported observations with much smaller spacer group. ${ }^{\mathbf{1 8 , 2 0}}$ Therefore, increase in helical content, in this case is governed by stronger hydrophobic microdomains which not only limit the unfolding but also compress or increase the $\alpha$-helical
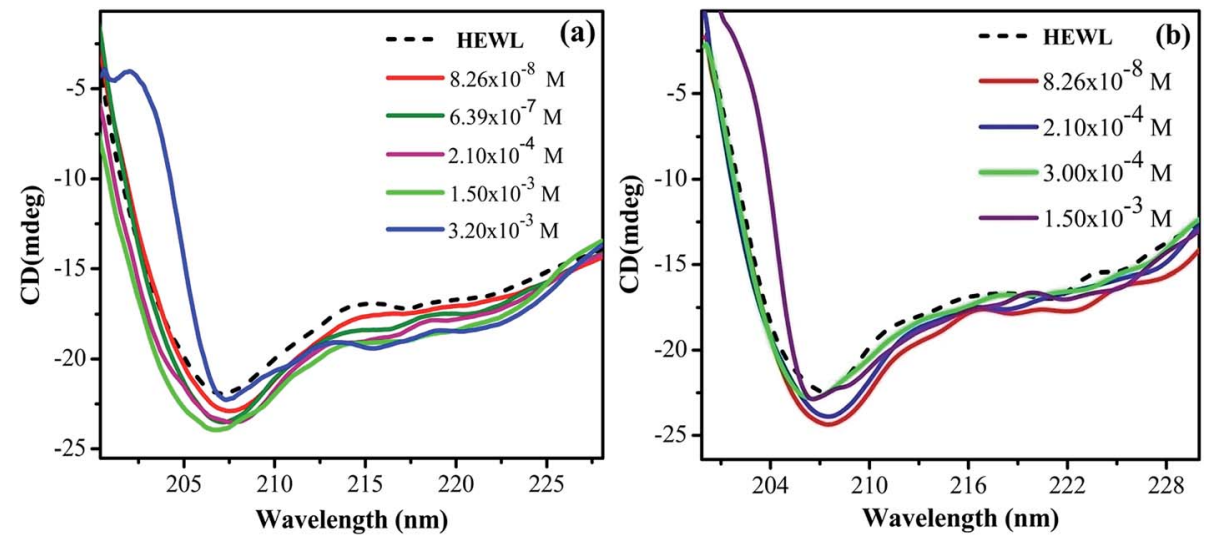

Fig. 1 Far-UV CD spectra of HEWL as a function of increase in concentration of (a) $M_{16}$ and (b) $G_{16}$ at $298 \mathrm{~K}$. 
content of the protein ${ }^{20}$ by interacting with the non-polar residues of the protein. These results also suggested that $\mathrm{G}_{16}$ stabilizes the secondary structure of protein up to considerable high concentration range even beyond its cmc value $(3.63 \times$ $10^{-6} \mathrm{M}$ to $\left.3.00 \times 10^{-4} \mathrm{M}\right)$. Whereas, a decrease in the $\alpha$-helical content was observed in the case of $\mathrm{M}_{16}$ at $3.20 \times 10^{-3} \mathrm{M}$ thus micelles of single chain surfactant stabilize the protein to considerable low concentration range $\left(2.10 \times 10^{-4} \mathrm{M}\right.$ to $1.50 \times$ $10^{-3} \mathrm{M}$ ) as compared to its gemini counterpart. Nevertheless, at very high surfactant concentration $\left(\mathrm{M}_{16}\right.$ and $\mathrm{G}_{16}$ respectively) excess micellar structures form intrachain hydrophobic interactions in the protein which are replaced by the electrostatic repulsive forces between the micellar aggregates, which is possibly the reason for decrease in the $\alpha$-helical content of $\mathrm{HEWL}^{20}$ as explained by Gull et $a .^{20}$ in a study with gemini surfactant and HSA.

For understanding, the conformational changes imparted by both the surfactants more clearly, near-UV CD experiments were done. The typical near-UV CD spectra (Fig. 3) of untreated HEWL gives positive triplet like signal from 280 to $300 \mathrm{~nm}$ range. This signal is indicative of lysozyme's active conformation. ${ }^{49}$ In addition, the weak negative band at $295 \mathrm{~nm}$ has been attributed to Trp108, which is associated with the active site. ${ }^{50}$ This gives direct insight for monitoring the environment of the active site of the enzyme.

It can be observed from the near-UV CD spectra shown in Fig. 3(a) that addition of $\mathrm{M}_{16}$ from concentration range $8.26 \times$ $10^{-8} \mathrm{M}$ to $1.50 \times 10^{-3} \mathrm{M}$ stabilizes the tertiary structure of the protein with intact active conformation as also observed by farUV CD results. After this, a significant fall in the native conformation with diminished peaks in $280-300 \mathrm{~nm}$ regions was observed. This indicates that at these concentrations the micellar structure of $\mathbf{M}_{16}$ strongly interferes with the tertiary structure of HEWL. ${ }^{50}$ The weak peak at $295 \mathrm{~nm}$ got almost diminished suggesting that the active site of the enzyme got significantly affected at higher micellar concentration and such disruption by different surfactants have been observed earlier. ${ }^{51}$ On the other hand, it can be clearly observed from Fig. 3(b) that no change in the tertiary structure of HEWL was monitored even at a very high concentration of $\mathrm{G}_{16}$ (from $8.26 \times 10^{-8}$ to $2.11 \times$ $10^{-2} \mathrm{M}$ ) and found to be resistant to its addition. These observations suggest that $\mathrm{G}_{16}$ at very high concentration do not interferes with the tertiary structure of the protein, though it affects the local secondary structure of HEWL as observed in farUV CD results. This type of unusual protein conformation has also been reported elsewhere. ${ }^{52,53}$ Some other gemini's on interaction with proteins like HSA, are also found to increase their tertiary structure. ${ }^{20}$

\subsection{Steady-state fluorescence measurements}

Steady-state fluorescence spectroscopy is sensitive technique to evaluate the changes in the microenvironment around the fluorophore and to monitor the tertiary structure of the protein. HEWL has six tryptophan molecules out of which steady state fluorescence data have shown that $80 \%$ of the fluorescence in the native protein comes from Trp62 and Trp108. ${ }^{54}$ These two residues reside in the hydrophobic core (Trp62 is most exposed) of HEWL and their intensity for fluorescence is highly dependent on the microenvironment. The emission spectrum was monitored by exciting HEWL at $280 \mathrm{~nm}$ and monitoring the emission at $342 \mathrm{~nm}$. This gives an overall picture of the globular protein folding. ${ }^{20}$

With the addition of $\mathrm{M}_{16}$ concentration from $8.26 \times 10^{-8}$ to $1.20 \times 10^{-4} \mathrm{M}$ in HEWL, no change (Fig. 4(a)) in the intensity was measured and the spectra overlap on the native HEWL, suggesting native like microenvironment around the fluorophores. At $\mathrm{M}_{16}$ concentration $2.10 \times 10^{-4} \mathrm{M}$ increase in the intensity was monitored, the maximum increase was observed at concentration $1.50 \times 10^{-3} \mathrm{M}$. This may suggest that $\mathbf{M}_{16}$ micelles providing a structural moiety to HEWL where fluorophores may suppress the internal quenching which otherwise interferes with their fluorescence. Thus, from the results, it can be interpreted that HEWL conformational changes observed in far-UV CD results lead to the exposure of Trp and Tyr molecules to a more flexible environment by $\mathbf{M}_{16}$ micelles which can also be related to HEWL compact structure. ${ }^{55}$ Such results have also been observed by Celej et al. ${ }^{12}$ At concentrations $3.2 \times 10^{-3} \mathrm{M}$ to $2.11 \times 10^{-2} \mathrm{M}$ the spectra showed a sharp decrease (Fig. 4(a)).
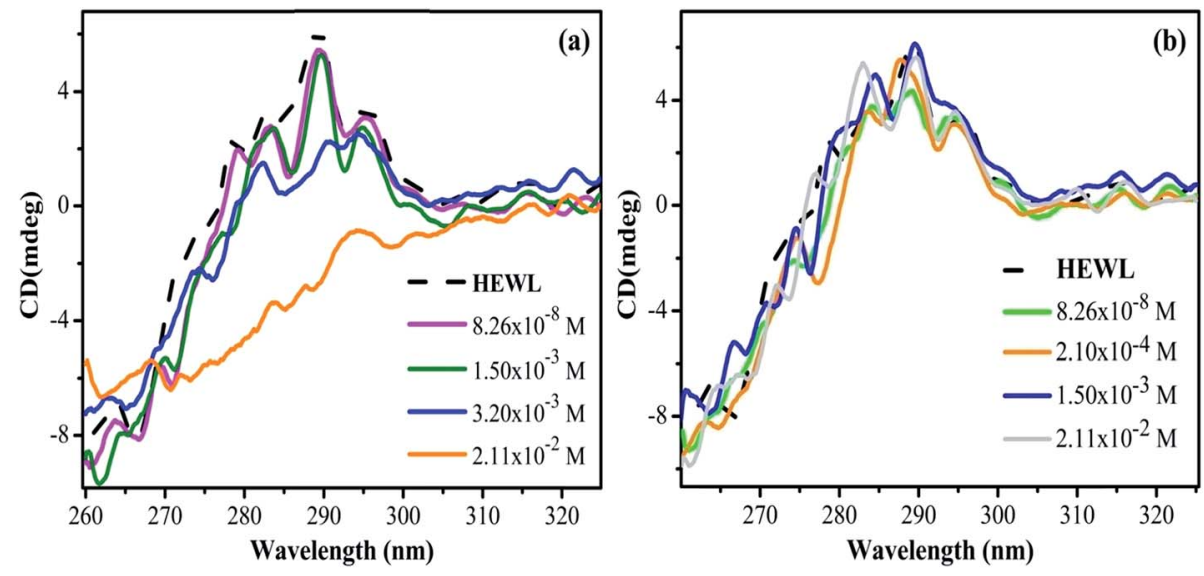

Fig. 3 Near UV-CD spectra of HEWL as a function of increase in concentration of (a) $M_{16}$ and (b) $G_{16}$ at $298 \mathrm{~K}$. 

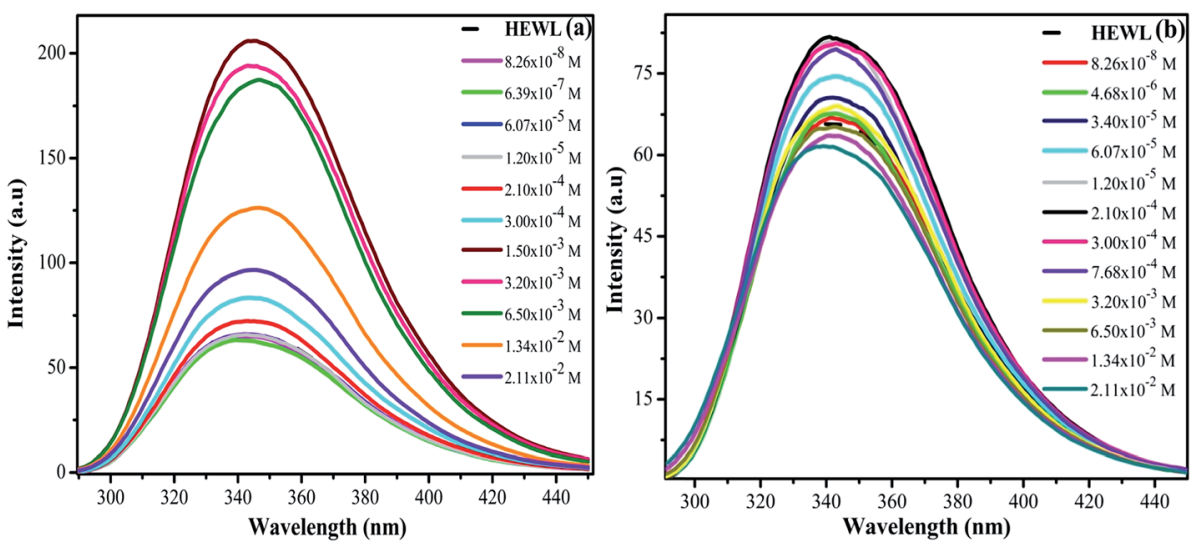

Fig. 4 Steady-state fluorescence spectra of HEWL with increase in concentration (a) $M_{16}$ and (b) $G_{16}$ from $8.26 \times 10^{-8}$ to $2.11 \times 10^{-2} \mathrm{M}$ at $298 \mathrm{~K}$.

This observation suggests that at these mentioned concentration the $\mathbf{M}_{16}$ micelles strongly interfere with the tertiary structure of HEWL that leads to its unfolding which is also confirmed by near-UV CD results at these concentrations.

On the other hand, the addition of various concentrations of $\mathrm{G}_{16}$ didn't produce a much pronounced effect on the intensity of HEWL unlike of $\mathrm{M}_{16}$ (Fig. 4(b)). Similar kind of result was also observed by Amiri et al. ${ }^{17}$ in which $\mathrm{G}_{16}$ treated RNase A showed minor changes in absorbance as well as fluorescence spectra. They attributed this effect due to the low charge density on $\mathrm{G}_{16}$ as also observed in the present study. Li et al. ${ }^{56}$ also experienced such observations with much decreased fluorescence intensity with increase in spacer length of gemini surfactants. The intensity of the spectra remained almost constant from $8.26 \times$ $10^{-8} \mathrm{M}$ to $3.4 \times 10^{-4} \mathrm{M} \mathrm{G}_{16}$ in a similar way as observed with $\mathrm{M}_{16}$ at its lower concentrations. A subtle increase in intensity was observed at concentration $6.07 \times 10^{-5} \mathrm{M}$ to $2.10 \times 10^{-4} \mathrm{M}$. As mentioned above this subtle increase in the intensity can be attributed to the compact tertiary structure as well as the increase in the $\alpha$-helical content of HEWL as observed through far and near-UV CD experiments. The spectrum slightly decreased at concentration $3.0 \times 10^{-4} \mathrm{M}$ and this can be attributed due to the destabilization of $\alpha$-helix as observed in far-UV CD results. The decrease in fluorescence with a subtle blue shift of $4 \mathrm{~nm}(\sim 342$ to $\sim 338 \mathrm{~nm})$ was observed at concentration $2.11 \times 10^{-2} \mathrm{M}$ suggesting movement of the fluorophore to a more hydrophobic environment may be because of some loss of $\alpha$-helical content at high concentration of $\mathrm{G}_{16}$ micelles. The difference in the change of the fluorescence intensity of both the ligands can be more clearly visualized from the graph plotted between maximum fluorescence intensity $\left(F_{\max }\right)$ as a function of increase in the concentration of $\mathbf{M}_{16}$ and $\mathrm{G}_{16}$ (Fig. 5).

These observations give the possible binding mechanism of both the surfactants with HEWL. Apart from the difference in charge density on the surface of $\mathrm{M}_{16}$ and $\mathrm{G}_{16}$ which governs the binding with HEWL, other possible reason for discrepancy in the intensity change of HEWL in presence of respective surfactants lies on the fact that possibly the micellar shapes of both the surfactants have different structure which produces different effect on the secondary and tertiary structure of the protein. ${ }^{7}$ Thus, more research is needed to confirm these possibilities.

Synchronous fluorescence spectroscopy was also done in order to decipher the involvement of Trp and Tyr molecule during the interaction of $\mathrm{M}_{16}$ and $\mathrm{G}_{16}$ with HEWL respectively. It was observed (Fig. 1S and $2 \mathrm{~S} \dagger$ ) that in both the cases the Tyr molecule marginally got affected and the major effect of both the ligands was observed on Trp molecule. Effect of $\mathrm{G}_{16}$ on Trp microenvironment (Fig. 2S(a)†) at higher concentration depicts a blue shift which is same as observed in steady-state fluorescence experiment. This observation suggests the movement of Trp residues to a less solvent exposed environment at high $\mathrm{G}_{16}$ concentrations.

\subsection{Time resolved spectroscopy}

Structural and conformational dynamics of proteins can be thoroughly analyzed by measuring steady-state fluorescence spectroscopy in combination with studying the fluorescence lifetime of these molecules. ${ }^{55,57}$ In case of HEWL, it has been

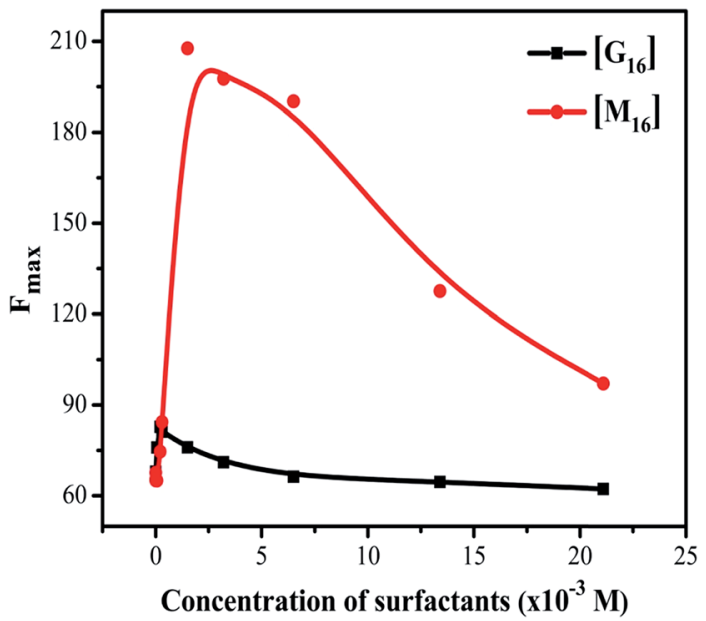

Fig. 5 Difference in variation in $F_{\max }$ of $\mathrm{HEWL}$ with increased concentration of $\mathrm{M}_{16}$ and $\mathrm{G}_{16}$. 
reported that Trp62 has the longest lifetime of $\sim 2.5-2.8 \mathrm{~ns}(\tau$ value) as it is most exposed to the solvent where as Trp108 (buried in the hydrophobic core) has the lifetime of $\sim 1.5-1.7$ $\mathrm{ns},{ }^{54,58}$ also the lifetime decay values are $\mathrm{pH}$ dependent. ${ }^{58}$ Solvent exposure is not only the reason for Trp62 longer lifetime. The fluorescence lifetime of proteins is highly affected by the quenching effect of the nearby sulfur containing groups. These groups are effective collision quenchers of indole fluorescence. Trp62 does not reside near cystine (involved in disulfide bond formation) or methionine residues; this increases its lifetime. ${ }^{58}$ Trp108 also has very less contact with the cystine residues. Trp108 and Trp28 are associated with methionine residues however methionine is not involved in fluorescence quenching. It's mainly Trp62 which decreases the fluorescence lifetime of Trp108 through energy transfer process. $^{54}$ Other three Trp63, Trp111 and Trp123 have high contact with cystine residues which contributes to their shorter lifetimes that is $\sim 0.5 \mathrm{~ns}^{.58}$

The presented life time values (Tables S2 and S3†) in the present study are markers of the microenvironment of the fluorophore, where $\tau_{3}, \tau_{2}$ and $\tau_{1}$ values are designated to Trp62, Trp108, and life time of other Trp as discussed above. The relative amplitude here is regarded as the relative population of Trp62, Trp108 and other remaining Trp in the excited states. The value of $\tau$ is thus system dependent. Mandal et al. ${ }^{57}$ illustrated that when quenching favorably occurs by different influencing interactions the value of $\tau$ can decrease, when ligand does not affect the fluorophore the $\tau$ value remains unaffected, and on removing the quenching factors the $\tau$ value even can increase. Increase/decrease in fluorescence lifetime was also observed in the unfolding/refolding studies of proteins as reported by Anand et al. ${ }^{55}$

The obtained $\tau_{3}, \tau_{2}$ and $\tau_{1}$ values of untreated HEWL (Tables S2 and S3†) are in fair agreement with the above mentioned values. This difference in the $\tau_{\text {avg }}$ of HEWL with increased concentration of $\mathrm{M}_{16}$ and $\mathrm{G}_{16}$ can be more clearly visualized through Fig. 7 . In the case of $\mathrm{M}_{16}$, from the spectra represented in Fig. 6(a), it can be clearly analyzed that calculated $\tau_{\text {avg }}$ values remained almost constant from $\mathbf{M}_{16}$ concentrations between $8.26 \times 10^{-8} \mathrm{M}$ to $6.07 \times 10^{-5} \mathrm{M}$ indicating compactness maintained by the surfactant. A subtle increase in $\tau_{\text {avg }}$ value was observed at concentration $3.00 \times 10^{-4} \mathrm{M}$ to $1.50 \times 10^{-3} \mathrm{M}$. These observations are in accordance with our previous results suggesting structural stability provided by the $\mathbf{M}_{16}$ at these micellar concentrations. The $\tau_{\text {avg }}$ values (Table S2 $\uparrow$ and Fig. 6(a)) start decreasing at concentration $3.20 \times 10^{-3} \mathrm{M}$ to $2.11 \times 10^{-2} \mathrm{M}$. This observation can be attributed to the quenching effect which is mainly exhibited due to the presence of highly hydrophobic micellar aggregates of $\mathbf{M}_{16}$ at very high micellar concentrations which changes the conformation of HEWL and perturbs its secondary and tertiary structure. The quenching effect can be explained in accordance to the explanations given by Anand et $a l .{ }^{59}$ They explained the role of planarity of Trp indole ring at the ground and excited states. As the substrate interact with the Trp residue, it leads to distortion of the planarity of the indole ring which results in the reduction of fluorescence lifetime. ${ }^{59}$ Also, out of three lifetime values, Trp62 (most exposed) was found to be most effected in the present data. This suggests that lifetime of Trp residues is highly dependent upon its native position in a folded protein. Thus, the substrate in the present study is $\mathbf{M}_{16}$ micelles which at higher micellar concentrations distort the planarity of the Trp62 residue due to change in the overall conformation of HEWL which causes a change in the local environment around it and decrease in its lifetime as well as relative amplitude. In the case of $\mathrm{G}_{16}$, the $\tau_{\text {avg }}$ value (Table $\mathrm{S} 3 \uparrow$ and Fig. 6(b)) was found to be in the increasing order which can be attributed to the attainment of HEWL overall conformation where the fluorophores are possibly not being affected by the internal quenchers (relative amplitude of Trp residues other then Trp62). The relative contribution by longer component (Trp62) at very high $\mathrm{G}_{16}$ concentration was found to be decreased considerably (Table S3 $\dagger$ ), this happened because of the decreased $\alpha$-helical content, suggesting its movement to a less solvent exposed environment as observed in far-UV CD as well as in steady state fluorescence spectroscopy results (confirmed by blue shift).
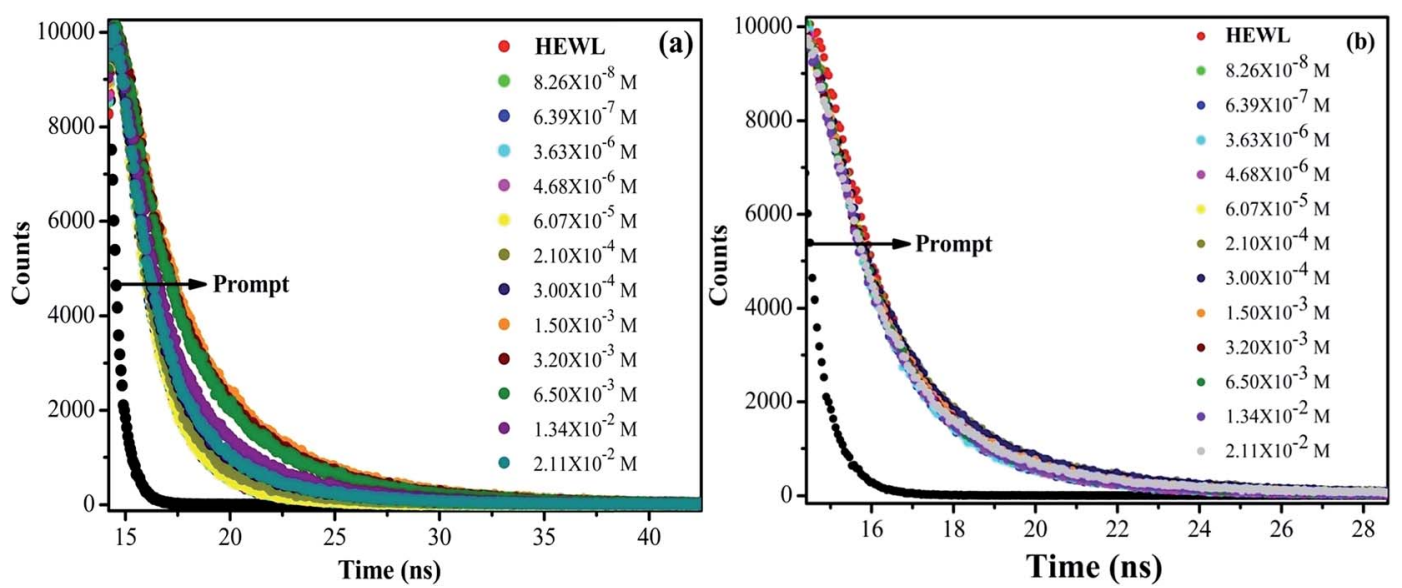

Fig. 6 Variation in fluorescence lifetime of HEWL as a function of increase in concentration of (a) $M_{16}$ and (b) $G_{16}$ at 298 K. 


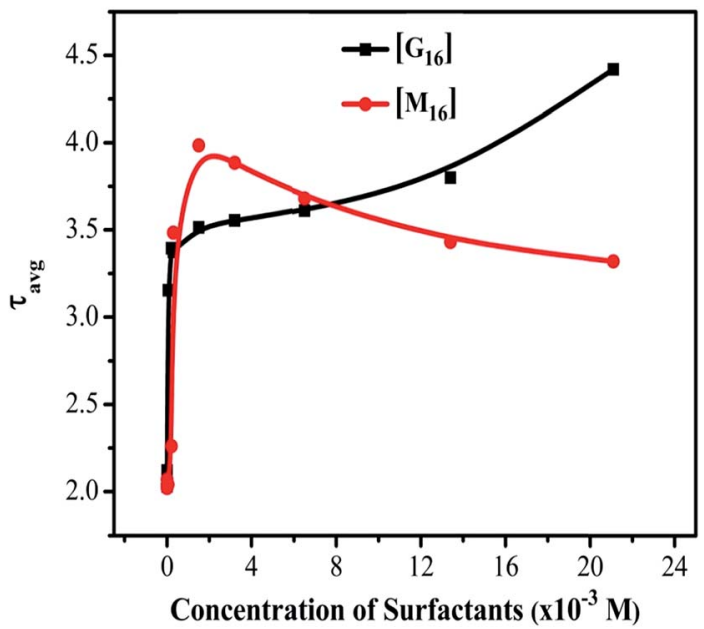

Fig. 7 Difference in variation of $\tau_{\text {avg }}$ of $H E W L$ with increased concentration of $\mathrm{M}_{16}$ and $\mathrm{G}_{16}$.

\subsection{UV-visible spectroscopy}

HEWL shows two absorption bands. One strong band arises due to the $\pi-\pi^{*}$ electronic transition of the peptide backbone $\mathrm{C}=\mathrm{O}$. It lies in between $200-230 \mathrm{~nm}$ and gives information about the scaffold of HEWL. ${ }^{60}$ Second absorption band can be seen at $280 \mathrm{~nm}$ involving $\mathrm{n}-\pi^{*}$ transitions which arise mainly due to the presence of aromatic amino acids (largely because of Trp). UV-visible spectroscopy was employed to monitor the effect of $\mathbf{M}_{16}$ and $\mathrm{G}_{16}$ on HEWL.

From Fig. 8(a) and (b), it can be clearly seen that the absorbance at $280 \mathrm{~nm}$ of HEWL substantially increases in both the cases. The variation in absorbance intensities can be more clearly analyzed by plotting a graph between absorbance values obtained at $280 \mathrm{~nm}$ as a function of increased concentration of $\mathrm{M}_{16}$ and $\mathrm{G}_{16}$ as shown in Fig. 9. In the case of $\mathrm{M}_{16}$, it can be clearly seen through the plot that the absorbance values remained almost constant from $8.26 \times 10^{-8} \mathrm{M}$ to $3.20 \times 10^{-3} \mathrm{M}$. At higher concentrations $\left(1.34 \times 10^{-2}\right.$ to $\left.2.11 \times 10^{-2} \mathrm{M}\right)$ absorbance values

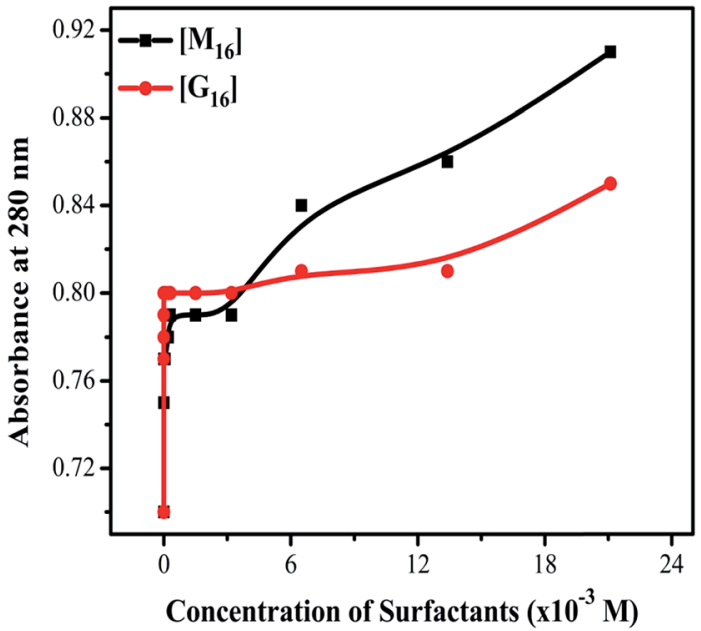

Fig. 9 Difference in variation of absorbance (at $280 \mathrm{~nm}$ ) of HEWL with increased concentration of $\mathrm{M}_{16}$ and $\mathrm{G}_{16}$.

sharply increased. On the other hand, the same trend was observed for $\mathrm{G}_{16}$ with not much changes in the absorbance value were observed at various concentrations. Additionally, more increase in absorbance values were observed at higher micellar concentrations of $\mathrm{G}_{16}\left(1.34 \times 10^{-2} \mathrm{M}\right.$ and $\left.2.11 \times 10^{-2} \mathrm{M}\right)$.

The small rise in absorbance is indicative that the addition of $\mathrm{G}_{16}$ and $\mathrm{M}_{16}$ hinders the penetration of light due to the compaction of HEWL and are in line with the observations reported by Mandal et al. ${ }^{57}$ on interaction of SDDS with HEWL. The hyperchromic effect observed at a higher micellar concentration (more pronounced in $\mathbf{M}_{16}$ ) with no shift is mainly attributed due to the conformational changes in the protein as observed in our previous results also. This indicates that at higher micellar concentration, due to strong electrostatic and hydrophobic interaction of $\mathrm{M}_{16}$ and $\mathrm{G}_{16}$ with HEWL causing exposure of chromophores to the bulk solvent and this result in increased observed absorbance values.
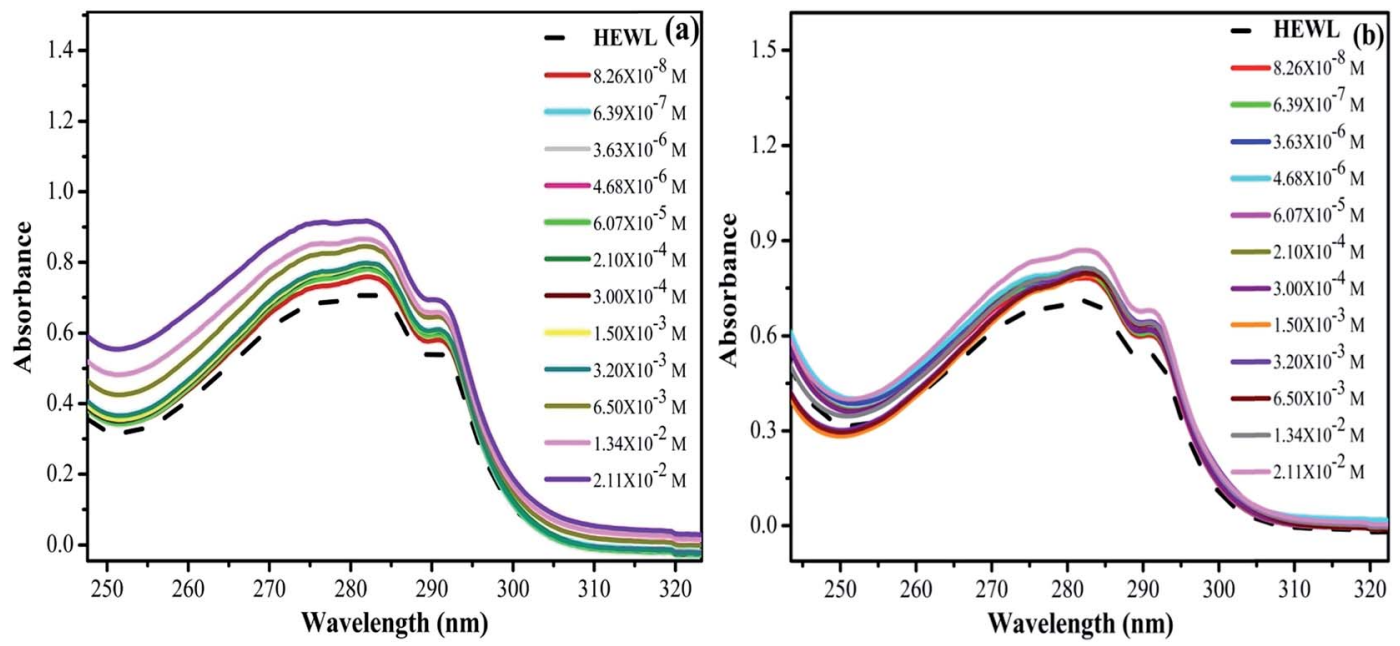

Fig. 8 UV-visible spectra of HEWL as a function of increase in concentration of (a) $M_{16}$ and (b) $G_{16}$ at $298 \mathrm{~K}$. 


\subsection{Extrinsic fluorescence spectroscopy}

The pyrene probe method is highly sensitive to even minor changes in the polarity of the medium and thus used for measuring cmc of surfactants in different mediums and ligandprotein interactions. ${ }^{61}$ Out of the five characteristic peaks $(\sim 375$ (I), 379 (II), 385 (III), 395 (IV) and 410 (V) nm) peak I is most sensitive to the non-polar environment and show a sharp decrease with increase in hydrophobicity. ${ }^{62}$ The ratio between the intensity of the emission peak I $\left(I_{1}\right)$ and III $\left(I_{3}\right)$ gives information about the polarity of the medium. ${ }^{63}$ The $I_{1} / I_{3}$ ratio decreases with increase in hydrophobicity of the medium. ${ }^{63}$ The reason behind this fact relies on the low solubility of pyrene in water and as the hydrophobicity of the medium increases, this ratio starts decreasing due to the interaction of pyrene molecules with the micellar aggregates. ${ }^{64}$ Direct and exact determination of cmc is not possible by using pyrene fluorescence probe method ${ }^{64}$ however its sensitiveness gives sufficiently good results. ${ }^{63}$ In a study by Akram et al. ${ }^{33}$ pyrene probe method has also been used to study the micropolarity of HEWL in the presence of different concentration of ligand. In the present study, pyrene probe method was used to analyze the alteration in the cmc value of respective surfactants in presence and absence of HEWL. It was also used to monitor the interaction of $\mathrm{M}_{16}$ and $\mathrm{G}_{16}$ in presence and absence of HEWL respectively.

It can be clearly seen from Fig. 10, in the presence of HEWL more decrease in the $I_{1} / I_{3}$ ratio curve was observed as compared to the decrease observed in an aqueous medium for both the surfactants. This observed decrease was comprehended to the increase in the hydrophobicity of the medium as discussed above. Non-polar pyrene molecule binds at the hydrophobic core of the HEWL through various weak interactions. The increase in concentration of $\mathrm{M}_{16}$ and $\mathrm{G}_{16}$ in the medium causes dislodging of pyrene molecules from the hydrophobic core of HEWL. This dislodging of pyrene molecule indicates interaction of $\mathrm{M}_{16}$ and $\mathrm{G}_{16}$ to the hydrophobic core of HEWL. After this stage, the dislodged pyrene starts residing within the micelle like aggregates of $\mathrm{M}_{16}$ and $\mathrm{G}_{16}$ as detailed by De et al. ${ }^{65}$ This can be clearly seen by the sharp decrease in the $I_{1} / I_{3}$ ratio. With further increase in $\mathrm{M}_{16}$ and $\mathrm{G}_{16}$ concentration, the $I_{1} / I_{3}$ ratio reached a constant value which indicates strong interaction of $\mathrm{M}_{16}$ and $\mathrm{G}_{16}$ with HEWL as compared to pyrene which is present in a constant environment. This observation suggests the complex formation of $\mathrm{M}_{16}$ and $\mathrm{G}_{16}$ with HEWL respectively and such results have also been reported earlier. ${ }^{61}$

In the absence of HEWL, pyrene senses the polar environment around it which can be observed through higher $I_{1} / I_{3}$ ratio. The decrease in the $I_{1} / I_{3}$ ratio is attributed to the solubilization of pyrene molecule in the hydrophobic part of the surfactant micelle as mentioned above.

The cmc values of $\mathrm{M}_{16}$ and $\mathrm{G}_{16}$ in presence and absence of HEWL were summarized in Table S4. $\dagger$ The $\mathrm{cmc}$ value of $\mathrm{M}_{16}$ and $\mathrm{G}_{16}$ in the absence of HEWL was found to be $2.40 \times 10^{-4} \mathrm{M}$ and $3.63 \times 10^{-6} \mathrm{M}$ which are in good agreement with the reported values. $^{34,37}$ The cmc value of $\mathrm{G}_{16}$ was found to be much lower as compared to $\mathrm{M}_{16}$. The low cmc value of $\mathrm{G}_{16}$ as compared to its single chain counterpart can be attributed to the fact that it has two $\mathrm{C}_{2} \mathrm{H}_{4} \mathrm{OH}$ group as compared to the single $\mathrm{C}_{2} \mathrm{H}_{4} \mathrm{OH}$ group in $\mathrm{M}_{16}$. This causes more hydrogen bond formation with water and with oxygen atom present in the head group. This results in the screening of repulsive forces between the head groups, which imposes the aggregate formation between them. ${ }^{34}$ Also, due to the characteristic properties of gemini surfactants, that is, two long hydrophobic chains and a spacer groups contributes to $\mathrm{G}_{16}$ lower cmc value. In the presence of HEWL, the $\mathrm{cmc}$ of $\mathrm{M}_{16}$ and $\mathrm{G}_{16}$ increased to $2.60 \times 10^{-4} \mathrm{M}$ and $3.91 \times 10^{-6} \mathrm{M}$. The delayed in cmc for both the cases in the presence of HEWL can be attributed to the obvious prior interaction of surfactants with the HEWL, after which they start forming micelles.

\subsection{Antibacterial activity assay of HEWL}

Activity profile of HEWL was determined by measuring the decrease in turbidity of Micrococcus luteus cells (cell lysis) in the presence of HEWL at $450 \mathrm{~nm}$ using UV-visible spectroscopy. The main residues which are involved in HEWL catalytic mechanism are Asp52 and Glu35. Glu35 execute proton donation and Asp52 work as a nucleophile that produces glycosyl intermediates. Trp62, Trp63 and Trp108 are also present in the substrate binding site and are sensitive to the microenvironment around
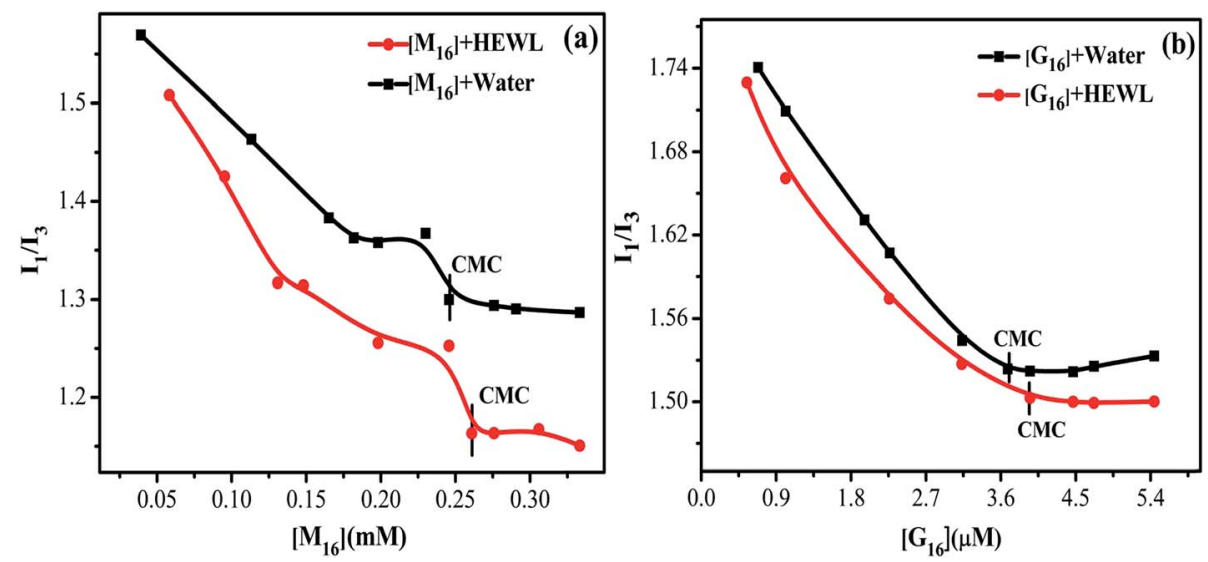

Fig. 10 Variation in $I_{1} / I_{3}$ of pyrene as a function of (a) $M_{16}$ concentration $\left(1.98 \times 10^{-2}\right.$ to $\left.3.30 \times 10^{-1} \mathrm{mM}\right)$ and (b) $G_{16}(0.34-5.44 \mu M)$ in absence and presence of HEWL. 

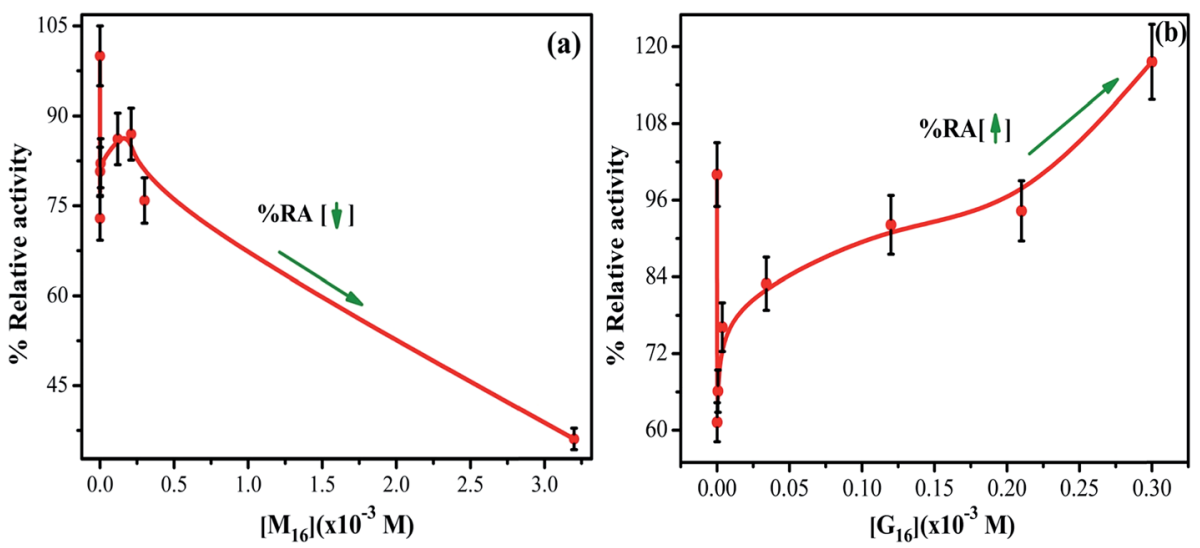

Fig. 11 Relative activity profile of HEWL as a function of increased concentrations of (a) $M_{16}$ and (b) $G_{16}$ (error bars represent $5 \%$ relative error).

them. This increases the significance of studying these residues residing in the active site of HEWL for monitoring the changes around the active site at different conditions.

The $\%$ RA of HEWL at different concentration of $\mathrm{M}_{16}$ and $\mathrm{G}_{16}$ was calculated by using eqn (6) and the values thus obtained were reported in Table S5. $\dagger$ In the case of the interaction of HEWL with $\mathrm{M}_{16}$ (Fig. 11(a)), with an increase in $\mathrm{M}_{16}$ concentration from $8.26 \times 10^{-8} \mathrm{M}$ to $3.63 \times 10^{-6} \mathrm{M} \%$ RA (relative activity) of HEWL was decreased by $\sim 20 \%$. This remained almost constant till $2.10 \times 10^{-4} \mathrm{M}$ and then further decreased by $\sim 25 \%$ at $3.00 \times 10^{-4} \mathrm{M}$ concentration of $\mathrm{M}_{16}$. The $\% \mathrm{RA}$ drastically decreased by $64 \%$ at $3.20 \times 10^{-3} \mathrm{M}$ concentration. In the case of $\mathrm{G}_{16}$ (Fig. 11(b)), 61\% activity was observed by HEWL in comparison to untreated HEWL at $8.26 \times 10^{-8} \mathrm{M} \mathrm{G}_{16}$ concentration. It gradually increases from $\sim 66 \%$ to $117 \%$ in the presence of $3.0 \times 10^{-4} \mathrm{M} \mathrm{G}_{16}$ concentration. After the above mentioned concentrations of respective surfactants, no antibacterial activity was observed.

In reviewing the literature it has been mentioned that activity of the surface active enzyme is dependent upon the surface per area of the enzyme with the surface of contact (in the present case it is bacterial membrane). HEWL is a surface active protein which acts on the surface of the bacterial membrane. It has been reported that HEWL even shows antibacterial activity at denatured conditions. ${ }^{66}$ Ibrahim et al. ${ }^{67}$ have illustrated the antibacterial activity of mutant and heat denatured lysozyme and confirmed that it is independent of its catalytic function. This in turn also proves that the antibacterial activity to some extent dependent on the structural components of this enzyme.

In the case of $\mathrm{M}_{16}$, its binding at the hydrophobic core of HEWL significantly affects its antibacterial activity in its monomeric and micellar concentrations, however, more pronounced effect was observed at micellar concentrations. Whereas, $\mathrm{G}_{16}$ substantially decreases the activity of HEWL at its monomeric concentrations, however, the activity was found to get gradually increased at its higher micellar concentration. Celej et al. ${ }^{12}$ reported that micelles of cationic surfactant like $\mathrm{CTABr}$ substantially increases the enzymatic activity of $\alpha$ chymotrypsin by stabilizing its secondary and tertiary structure. As by looking at the far-UV CD results (at concentration $3.00 \times$ $10^{-4} \mathrm{M}$ ) it can be concluded that increase in the antibacterial activity by $\mathrm{G}_{16}$ is not due to its stabilization effect on the secondary structure of HEWL. Apparently, this suggests that increased HEWL activity by $\mathrm{G}_{16}$ as compared to $\mathrm{M}_{16}$, is probably due to increased surface activity of HEWL by $\mathrm{G}_{16}$, nevertheless, these possibilities deserves further investigations. Also, such explanations have been previously mentioned by Dasgupta et $a l .{ }^{68}$ and Mitra et $a l .{ }^{69}$ As already mentioned in the introductory section, lysozyme has majorly $\alpha$-helix in its secondary structure present in the $\alpha$-domain (Fig. 12: a-domain). The active site of the protein lies in between the two domains ${ }^{26}$ (Fig. 12). It seems that, at very high concentration these micellar (a)

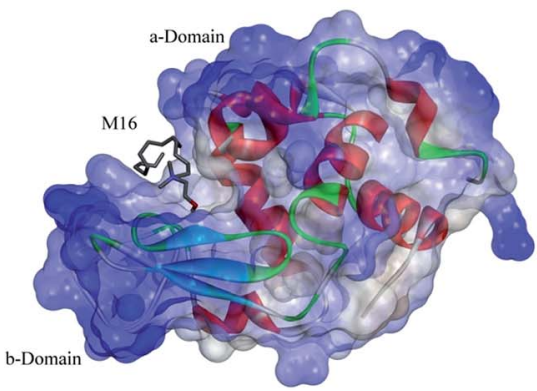

(b)

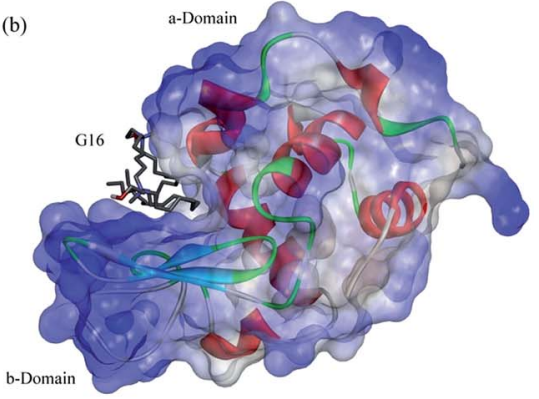

Fig. 12 Binding of (a) $M_{16}$ and (b) $G_{16}$ in the active site of HEWL. 
structures strongly interfere with the overall integrity of the two domains and due to this no activity were observed at very high $\mathrm{G}_{16}$ and $\mathrm{M}_{16}$ concentrations. Thus, decrease in secondary structure; considerably affect the activity of HEWL. Such results has also been reported by Li et al. ${ }^{13}$ and are further confirmed from our study.

\subsection{Molecular docking studies}

Docking studies were done to visualize and identify the possible binding sites in the complex formation between $\mathrm{M}_{16}$ and $\mathrm{G}_{16}$ with HEWL respectively. The docked conformation with lowest binding energy was selected. In the case of $\mathrm{M}_{16}$, it was found to be $-20 \mathrm{~kJ} \mathrm{~mol}^{-1}$ and in $\mathrm{G}_{16}$ it was $-17.99 \mathrm{~kJ} \mathrm{~mol}^{-1}$, where, Akram et $a l^{33}$ reported docking of gemini surfactants with very high binding energy. The negative sign shows spontaneity of the interaction. Through the binding energies it can be concluded that $\mathrm{G}_{16}$ binds slightly weaker with HEWL, as also inferred in the above discussions. Binding of $\mathrm{G}_{16}$ and $\mathrm{M}_{16}$ with HEWL was found to occur in the HEWL principle binding region lies between the two domains as can be seen in Fig. 12 (a $(\alpha)$ and b ( $\beta$ ) domains) and also reported by Akram et al. ${ }^{33}$

Leu75, Asn103, Ile98, Ala107, Asp52, Gln57, Ile58, Asn59, Trp62, Trp63 and Asp101 strongly influencing the $\mathbf{M}_{16}$-HEWL binding complex majorly through van der Waal's interactions and various electrostatic and hydrophobic interactions (Fig. 13). The weak hydrophobic pi-alkyl interaction was found between methyl group in the tail region of $\mathrm{M}_{16}$ and Trp63 residue $(6.86 \AA$ distance). Trp62 and Trp63 were found to strongly influence the complex through van der Waal's and hydrophobic interaction as the hydrophobic tail was also found to be in close proximity with these residues. One carbon hydrogen bond $(5.73 \AA$ distance) was also observed to form between Ala107 and methyl group present in the head region of the $\mathbf{M}_{16}$.

As can be seen in Fig. 14, binding of $\mathrm{G}_{16}$ with HEWL includes various weak interactions with Thr47, Asn46, Asp52, Trp108, Gln57, Asn59, Ile98, Ile58, Trp62, val109, Ala107, Asn103,

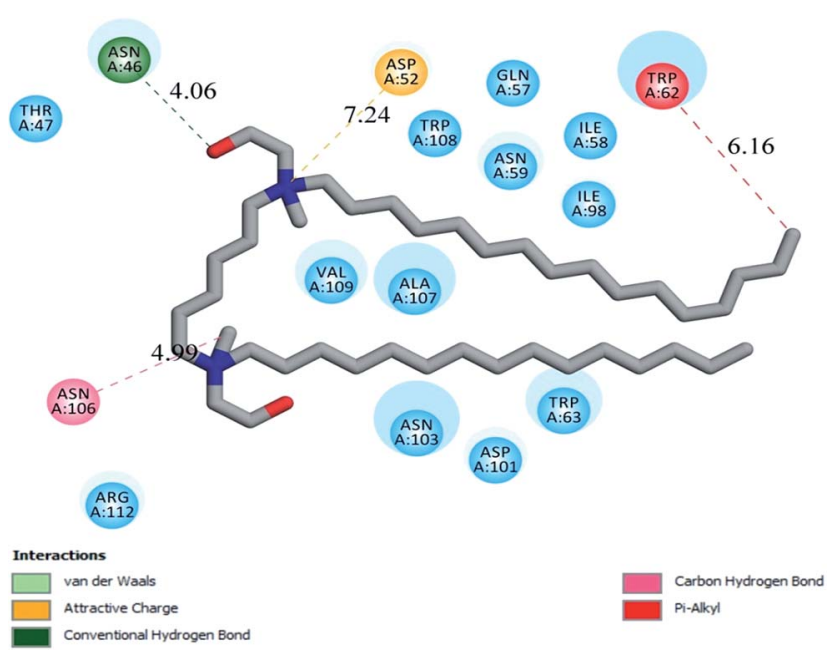

Fig. 13 Various interactions involved in the formation of $M_{16}-H E W L$ complex.

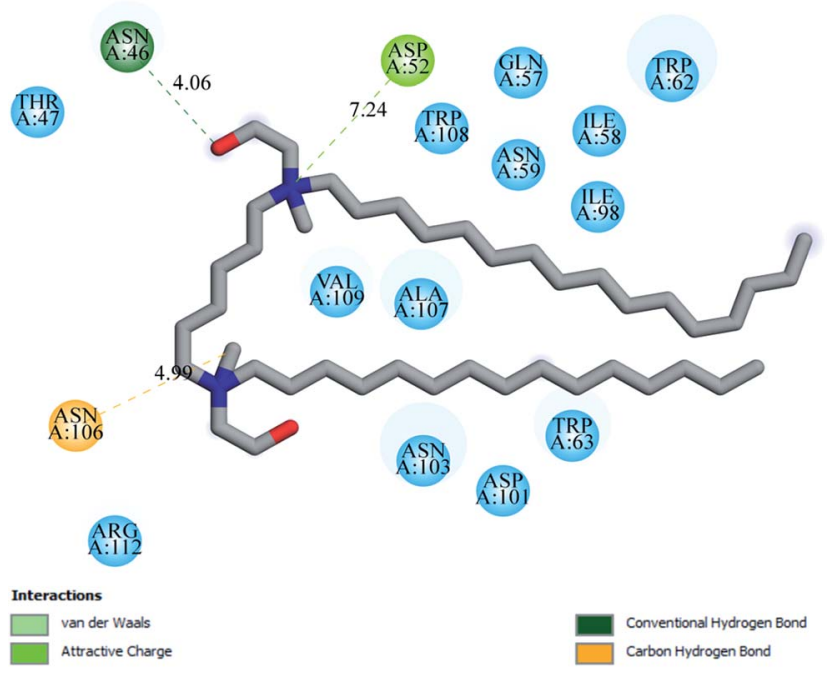

Fig. 14 Various interactions involved in the formation of $\mathrm{G}_{16}-\mathrm{HEWL}$ complex.

Asp101, Trp63, Arg112 and Asn106 residues out of which van der Waal's interactions playing a significant role. The nitrogen group of $\mathrm{G}_{16}$ is making electrostatic attractive interaction with the negatively charge Asp52 residues with a bond distance of $7.24 \AA$ A. As already mentioned, Asp52 is the major residue which acts as a nucleophile and forms glycosyl intermediate during the catalytic process. Due to this electrostatic interaction HEWL antibacterial activity tremendously affected when it interacts with the monomeric form of $\mathrm{G}_{16}$. Also, it can be clearly seen that one hydrogen bond was observed to form between Asn46 (at a distance of $4.06 \AA$ ) and hydroxyl group (shown as a red stick) present in the head region of $\mathrm{G}_{16}$ molecule. One other carbon hydrogen bond is also forming between Asn106 (at a distance of $4.99 \AA$ A) and methyl group present at the head region of $\mathrm{G}_{16}$ molecule. The hydrophobic tail of the $\mathrm{G}_{16}$ was found to be in close proximity with Trp63 and distant from the two major fluorophores Trp62 and Trp108. This may be attributed to low changes in absorbance as well as emission intensities observed in the spectroscopic experiments of the $\mathrm{G}_{16}$-HEWL complex.

\section{Conclusions}

We have brought in the difference between the interaction mechanism of cationic gemini surfactant and its monomeric counterpart with HEWL using standard spectroscopic techniques and molecular docking method. From the study, it can be concluded that surfactants used in the work have considerable effect on the structural stability of HEWL. The $\mathrm{G}_{16}$ was more evident in stabilizing the secondary (at higher micellar concentrations) as well as tertiary structure of HEWL at considerably high cmc value. At high $\mathrm{G}_{16}$ concentration apparently, the native HEWL becomes less solvent exposed may be due to aggregation and it can be said that protein might have adopted an unusual structural moiety where it has a compact tertiary structure with less pronounced helical content. On the other hand, $\mathbf{M}_{16}$ at higher concentrations affects the secondary 
as well as tertiary structure of the protein. This discrepancy in the effect of respective surfactant on HEWL conformation is attributed to the difference in the physiochemical properties of both the surfactants. These distinguished properties of such surfactants can prove to be useful in their applicability in different industries (cosmetics, food, feed). The detailed account on the time-resolved analysis of different $\tau$ values of fluorophores in HEWL on interaction with surfactants is new addition to the literature, nonetheless strewed information and associations are available in some reports. The antibacterial activity was also found to increase in the presence of gemini surfactant where single chain surfactant was found to decrease it substantially. Thus, this study can provide a better insight for the usage of this enzyme in enhancing its role in food preservation as well as a more efficient antibiotic. For future prospective more in vitro as well as in vivo studies are required for the above mentioned possible significance of this study.

\section{Acknowledgements}

Dr Rajan Patel greatly acknowledges the financial supports from Science and Engineering Research Board (EEQ/2016/000339 and SB/EMEQ-097/2013) and University Grant Commission New Delhi, India (F. No. 39-841/2010 (SR)). Dr Abbul Bashar Khan is thankful to Science and Engineering Research Board (SERB), New Delhi for providing research grant with Sanction Order No. SB/FT/CS- 031/2013. Authors also thank DST for providing the FIST grant with Sanction Order No. (SR/FIST/LS$541 / 2012)$.

\section{References}

1 D. E. Otzen, Biochim. Biophys. Acta, 2011, 1814, 562-591.

2 C. Tanford, Y. Nozaki, J. A. Reynolds and S. Makino, Biochemistry, 1974, 13, 2369-2376.

3 T. E. Creighton, Curr. Opin. Struct. Biol., 1991, 1, 5-16.

4 A. Hvidt and P. Westh, J. Solution Chem., 1998, 27, 395-402.

5 A. Yonath, A. Podjarny, B. Honig, A. Sielecki and W. Traub, Biochemistry, 1977, 16, 1418-1424.

6 J. A. Reynolds and C. Tanford, J. Biol. Chem., 1970, 245, 51615165.

7 D. E. Otzen, Biophys. J., 2002, 83, 2219-2230.

8 N. Gull, P. Sen and R. H. Khan, J. Biochem., 2007, 141, 261268.

9 N. Gull, S. Kumar, B. Ahmad and R. H. Khan, Colloids Surf., $B$, 2006, 51, 10-15.

10 M. N. Jones, H. A. Skinner, E. Tipping and A. Wilkinson, Biochem. J., 1973, 135, 231-236.

11 A. Few, R. Ottewill and H. Parreira, Biochim. Biophys. Acta, 1955, 18, 136-137.

12 M. S. Celej, M. G. D. Andrea, P. T. Campana, G. D. Fidelio and M. L. Bianconi, Biochem. J., 2004, 378, 1059-1066.

13 Q. Li, T. Zhai, K. Du, Y. Li and W. Feng, Colloids Surf., B, 2013, 112, 315-321.

14 R. C. Lu, J. X. Xiao, A. N. Cao, L. H. Lai, B. Y. Zhu and G. X. Zhao, Biochim. Biophys. Acta, 2005, 1722, 271-281.
15 M. L. Guzman, M. R. Marques, M. E. O. Me and E. S. Stippler, Results Pharma Sci., 2016, 6, 15-19.

16 R. Amiri, A. K. Bordbar and D. V. Laurents, J. Phys. Chem. B, 2014, 118, 10633-10642.

17 R. Amiri, A. K. Bordbar, D. V. Laurents, A. R. Khosropour and I. Mohammadpoor-Baltork, Int. J. Biol. Macromol., 2012, 50, 1151-1157.

18 N. Gull, P. Sen and R. H. Khan, Langmuir, 2009, 25, 1168611691.

19 Y. Li, M. Cao and Y. Wang, J. Phys. Chem. B, 2006, 110, 18040-18045.

20 N. Gull, P. Sen and R. H. Khan, J. Biochem., 2009, 145, 67-77.

21 Y. Han and Y. Wang, Phys. Chem. Chem. Phys., 2011, 13, 1939-1956.

22 M. A. Mir, J. M. Khan, R. H. Khan, G. M. Rather and A. A. Dar, Colloids Surf., B, 2010, 77, 54-59.

23 R. Patel, M. U. H. Mir, U. K. Singh, I. Beg, A. Islam and A. B. Khan, J. Colloid Interface Sci., 2016, 484, 205-212.

24 R. Patel, M. ud din Parray, U. K. Singh, A. Islam, P. Venkatesu, S. Singh and H. B. Bohidar, Colloids Surf., A, 2016, 508, 150-158.

25 F. Chiti and C. M. Dobson, Annu. Rev. Biochem., 2006, 75, 333-366.

26 A. Sethuraman and G. Belfort, Biophys. J., 2005, 88, 1322-1333.

27 N. A. Fazili, W. F. Bhat and A. Naeem, Int. J. Biol. Macromol., 2014, 64, 36-44.

28 B. Mandal, S. Mondal, A. Pan, S. P. Moulik and S. Ghosh, Colloids Surf., A, 2015, 484, 345-353.

29 M. D. Lad, V. M. Ledger, B. Briggs, R. J. Green and R. A. Frazier, Langmuir, 2003, 19, 5098-5103.

30 K. N. Vennila and D. Velmurugan, Acta Crystallogr., Sect. F: Struct. Biol. Cryst. Commun., 2011, 67, 1662-1665.

31 A. Chatterjee, S. Moulik, P. Majhi and S. Sanyal, Biophys. Chem., 2002, 98, 313-327.

32 W. Gospodarczyk and M. Kozak, Colloid Polym. Sci., 2015, 293, 2855-2866.

33 M. Akram, I. A. Bhat and D. Kabir ud, RSC Adv., 2015, 5, 102780-102794.

34 D. Tikariha, N. Singh, M. L. Satnami, K. K. Ghosh, N. Barbero and P. Quagliotto, Colloids Surf., A, 2012, 411, 1-11.

35 M. Borse, V. Sharma, V. Aswal, N. K. Pokhriyal, J. V. Joshi, P. S. Goyal and S. Devi, Phys. Chem. Chem. Phys., 2004, 6, 3508-3514.

36 R. Steiner, Biochim. Biophys. Acta, 1964, 79, 51-63.

37 S. S. Borse and T. J. Patil, J. Chem. Pharm. Res., 2014, 6, 904911.

38 J. R. Lakowicz, Principles of fluorescence spectroscopy, Springer Science \& Business Media, 2013.

39 Q. Yue, T. Shen, C. Wang, C. Gao and J. Liu, Int. J. Spectrosc., 2012, 2012, 1-9.

40 K. Kalyanasundaram and J. K. Thomas, J. Am. Chem. Soc., 1977, 99, 2039-2044.

41 M. Yan, B. Li and X. Zhao, Food Chem., 2010, 122, 1333-1337.

42 J. Tian, Y. Zhao, X. Liu and S. Zhao, Luminescence, 2009, 24, 386-393.

43 G. C. Chen and J. T. Yang, Anal. Lett., 1977, 10, 1195-1207. 
44 N. J. Greenfield and G. D. Fasman, Biochemistry, 1969, 8, 4108-4116.

45 D. Shugar, Biochim. Biophys. Acta, 1952, 8, 302-309.

46 H. M. Berman, J. Westbrook, Z. Feng, G. Gilliland, T. N. Bhat, H. Weissig, I. N. Shindyalov and P. E. Bourne, Nucleic Acids Res., 2000, 28, 235-242.

47 N. C. Price, Biotechnol. Appl. Biochem., 2000, 31, 29-40.

48 Y. Wang, R. Guo and J. Xi, J. Colloid Interface Sci., 2009, 331, 470-475.

49 G. D. Fasman, in Circular Dichroism and the Conformational Analysis of Biomolecules, Springer, 1996, pp. 381-412.

50 T. Knubovets, J. J. Osterhout and A. M. Klibanov, Biotechnol. Bioeng., 1999, 63, 242-248.

$51 \mathrm{~W}$. Zhu and T. A. Keiderling, Biochim. Biophys. Acta, 2013, 1834, 593-600.

52 A. Ratnaparkhi, S. A. Muthu, S. M. Shiriskar, R. R. Pissurlenkar, S. Choudhary and B. Ahmad, J. Biomol. Struct. Dyn., 2015, 33, 1866-1879.

53 S. Venkataramani, J. Truntzer and D. R. Coleman, J. Pharm. BioAllied Sci., 2013, 5, 148.

54 J. M. Beechem and L. Brand, Annu. Rev. Biochem., 1985, 54, 43-71.

55 U. Anand and S. Mukherjee, Biochim. Biophys. Acta, 2013, 1830, 5394-5404.

56 Y. Li, X. Wang and Y. Wang, J. Phys. Chem. B, 2006, 110, 8499-8505.
57 B. Mandal, S. Ghosh and S. Moulik, New J. Chem., 2016, 40, 4617-4624.

58 C. Rmoso and L. S. Forster, J. Biol. Chem., 1975, 250, 37383745 .

59 U. Anand and S. Mukherjee, Phys. Chem. Chem. Phys., 2013, 15, 9375-9383.

60 J. Wang, X. Yang, J. Wang, C. Xu, W. Zhang, R. Liu and W. Zong, New J. Chem., 2016, 40, 3738-3746.

61 M. Kumari, J. K. Maurya, M. Tasleem, P. Singh and R. Patel, J. Photochem. Photobiol., B, 2014, 138, 27-35.

62 G. Bains, A. B. Patel and V. Narayanaswami, Molecules, 2011, 16, 7909-7935.

63 K. Ananthapadmanabhan, E. Goddard, N. Turro and P. Kuo, Langmuir, 1985, 1, 352-355.

64 M. Vasilescu, D. Angelescu, M. Almgren and A. Valstar, Langmuir, 1999, 15, 2635-2643.

65 S. De, A. Girigoswami and S. Das, J. Colloid Interface Sci., 2005, 285, 562-573.

66 W. Carrillo, A. Garcia-Ruiz, I. Recio and M. V. MorenoArribas, J. Food Prot., 2014, 77, 1732-1739.

67 H. R. Ibrahim, T. Matsuzaki and T. Aoki, FEBS Lett., 2001, 506, 27-32.

68 A. Dasgupta, D. Das, R. N. Mitra and P. K. Das, J. Colloid Interface Sci., 2005, 289, 566-573.

69 R. N. Mitra, A. Dasgupta, D. Das, S. Roy, S. Debnath and P. K. Das, Langmuir, 2005, 21, 12115-12123. 